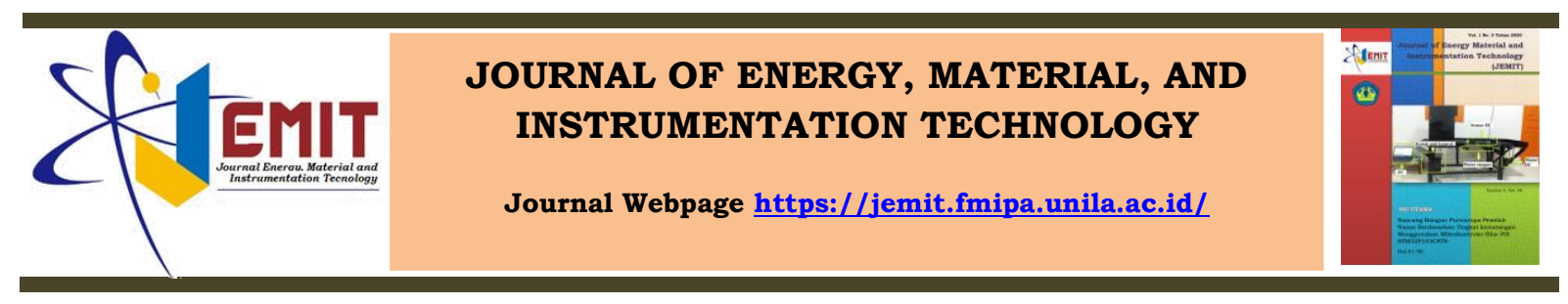

\title{
Analisis Suhu Dan Konsentrasi Karbondioksida dalam Kotak Pendingin Terhadap Susut Bobot dan Umur Simpan Buah Nanas (Ananas Comosus L. Merr) Berbasis MIT App Inventor 2
}

\author{
Yulinda Nugraeni*, Sri Wahyu Suciyati, Gurum Ahmad Pauzi, dan Amir Supriyanto
}

Jurusan Fisika, Universitas Lampung, Bandar Lampung, Indonesia, 35141

\section{Article Information}

Article history:

Received April $4^{\text {th }}, 2020$

Received in revised form

May 20th 2020

Accepted June $17^{\text {rd }}, 2020$

\section{Keywords:}

Pineapple, Temperature, carbon dioxide, ESP8266, Android

\begin{abstract}
Shrinkage of weight loss and shelf life of pineapples is influenced by high temperatures and $\mathrm{CO} 2$ concentrations. This study aims to analyze the influence of temperature and $\mathrm{CO} 2$ concentration on weight loss and shelf life pineapple in a fridge cooler. The analysis data is obtained from a monitoring tool that has even the ESP8266 module to connect the Arduino with wifi through an application made with MIT App Inventor 2 so that data can be displayed with android. The downside of this application is that if the cellular data network is weak or non-existent, data recording will stop. The results showed that the monitoring tool was able to send data successfully. During data collection, the temperature was $7.820 \mathrm{C}-11.050 \mathrm{C}$, the CO2 concentration was 457.20 ppm - 490.77 ppm, the weight loss on ripe pineapple was $1.84 \%, 2.63 \%$, and the weight loss on raw fruit $1.36 \%-3.52 \%$. Then from these data the $\mathrm{CO} 2$ concentration affects the respiration process, respiration affects the decay process. Whereas temperature affects the physical changes of pineapple fruit so that the shelf life of pineapples can last up to 22 days.
\end{abstract}

\section{Informasi Artikel}

Proses artikel:

Diterima 4 April 2020

Diterima dan direvisi dari 20 Mei 2020

Accepted 17 Juni 2020

Kata kunci:

Nanas, Suhu,

Karbondioksida, ESP8266,

Android

\begin{abstract}
Abstrak
Penyusutan bobot dan umur simpan nanas dipengaruhi oleh suhu dan konsentrasi CO2 yang tinggi. Penelitian ini bertujuan untuk menganalisis pengaruh suhu dan konsentrasi CO2 terhadap susut bobot serta umur simpan buah nanas dalam kotak pendingin jenis kulkas. Data analisis didapat dari alat monitoring yang telah bahkan modul ESP8266 untuk menghubungkan Arduino dengan wifi melalui aplikasi yang dibuat dengan MIT App Inventor 2 sehingga data dapat ditampilkan dengan android. Kelemahan dari aplikasi ini jika jaringan data seluler lemah atau tidak ada maka perekaman data akan berhenti. Hasil penelitian didapatkan bahwa alat montoring berhasil mengirimkan data. Selama pengambilan data suhu sebesar 7,82 oC - 11,05 oC, konsentrasi CO2 sebesar 457,20 ppm - 490,77 ppm, susut bobot buah nanas matang sebesar $1,84 \%-2,63 \%$ dan susut bobot buah mentah sebesar 1,36 \% - 3,52 $\%$. Kemudian dari data tersebut konsentrasi $\mathrm{CO} 2$ berpengaruh pada proses respirasi, respirasi berpengaruh terhadap proses pembusukan. Sedangkan suhu berpengaruh pada perubahan fisik buah nanas sehingga didapatkan umur simpan buah nanas bertahan hingga 22 hari.
\end{abstract}

\section{Pendahuluan}

Nanas (Ananas comosus L. Merr) merupakan salah satu komoditas buah yang banyak dimanfaatkan masyarakat Indonesia untuk dikonsumsi. Pengaruh oksidasi karena penyimpanan yang salah juga akan membuat kualitas buah menjadi menurun. Pada dasarnya, Nanas setelah dipanen dikatakan masih hidup karena masih melakukan proses pernafasan seperti halnya manusia. Proses pernafasan tersebut adalah pengambilan gas 
Nugraeni Y, Suciyati SW, Pauzi GA, dan Supriyanto A, 2020, Analisis Suhu Dan Konsentrasi Karbondioksida dalam Kotak Pendingin Terhadap Susut Bobot dan Umur Simpan Buah Nanas (Ananas Comosus L. Merr) Berbasis MIT App Inventor 2, Jurnal of Energy, Material, and Instrumentation Technology, Vol. 1 No. 3, 2020

oksigen dari udara yang digunakan untuk pembakaran bahan-bahan organik, dan mengeluarkan gas karbondioksida $\left(\mathrm{CO}_{2}\right)$ serta air sebagai hasil sisa proses pembakaran tersebut (Winarno, 2004). Proses resprasi menghasilkan energi yang digunakan untuk melakukan proses-proses metabolisme lain, misalnya perubahan warna dari hijau menjadi kuning, pembentukan gula dari pati, pembentukan aroma dan sebagainya. Buah yang telah dipanen sebenarnya mengandung berbagai mikroorganisme yang menyebabkan dekomposisi.

Penelitian sebelumnya telah dilakukan seperti, Agustiningrum dkk (2014) membuat respiration chamber yang berfungsi sebagai tempat penyimpanan bahan yang terdiri dari pompa vakum dan keran yang dipasang pada bagian atas respiration chamber. Widyaningrum dkk (2018) melakukan penelitian menggunakan desain sistem kontrol dan monitoring kondisi udara pada controlled atmosphere storage berbasis mikrokontroler Arduino Uno. Argo dkk (2010) juga telah melakukan monitoring gas oksigen dan karbondioksida dalam penyimpanan buah dan sayur untuk mengendalikan laju proses metabolisme untuk memperpanjang umur simpan. Hasil penelitian tersebut diketahui bahwa bahan uji yang digunakan mengalami respirasi aerob yang membutuhkan $\mathrm{O}_{2}$ dan menghasilkan $\mathrm{CO}_{2}$. Selain itu juga membuktikan bahwa komoditas pasca panen tetap mengalami respirasi sehingga apabila tidak segera ditangani maka komoditas tersebut akan rusak atau membusuk.

Berdasarkan uraian tersebut, kami mencoba melakukan penelitian untuk memonitoring konsentrasi $\mathrm{CO}_{2}$ dan suhu selama proses respirasi didalam pendingin buah (jenis kulkas) sehingga dapat melakukan analisis pengaruh konsentrasi $\mathrm{CO}_{2}$ dan suhu terhadap umur simpan serta susut bobot pada buah nanas yang disimpan dalam kulkas. Pada penelitian ini digunakan software Arduino IDE sebagai pembuatan program monitoring. Data pengamatan dapat diterima melalui android menggunakan komunikasi wifi melalui aplikasi yang dibuat dengan MIT App Inventor 2.

\section{Metode Penelitian}

Alat dan bahan yang digunakan dalam penelitian ini adalah modul buah nanas, microsoft excel, miscrosoft word, sketch up, MIT App Inventor, kulkas, timbangan digital, ESP8266, sensor DS18B20, RTC DS3231, sensor MH-Z14a, sensor LM358N, modul mikrokontroler Arduino Mega 2560, android dan personal computer.

\subsection{Pengambilan Data}

Pengambilan data menggunakan alat (Hidayatullah, 2020) ditunjukkan pada Gambar 1 dengan menambahkan modul ESP 8266 sebagai modul untuk menghubungkan Arduino dengan wifi agar dapat terhubung dengan android. Data diambil sejak nanas dimasukkan ke dalam kulkas hingga nanas mengalami kebusukan atau ditumbuhi jamur. Proses pengambilan data suhu dilakukan dalam kulkas dengan suhu yang terukur pada alat. Data konsentrasi $\mathrm{CO}_{2}$ dilakukan dalam kulkas saat buah dimasukkan sampai buah dikeluarkan dari kulkas. Pengambilan susut bobot buah dilakukan dengan mengukur massa buah dengan mengeluarkan buah setiap hari.

\section{Tombol Fungsi}

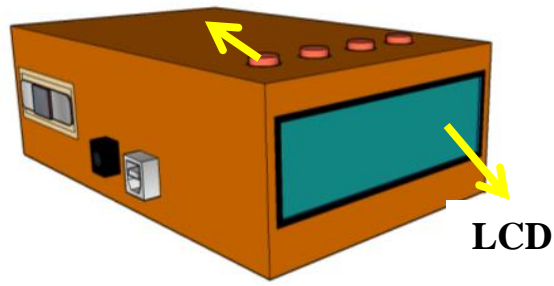

(a)

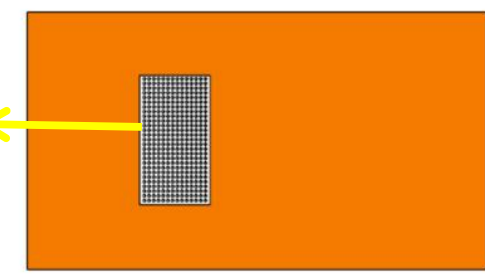

(c)

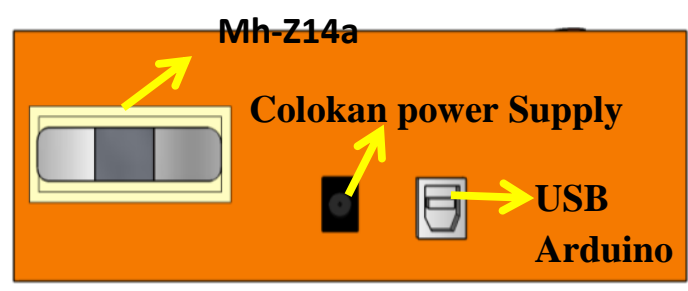

(b)

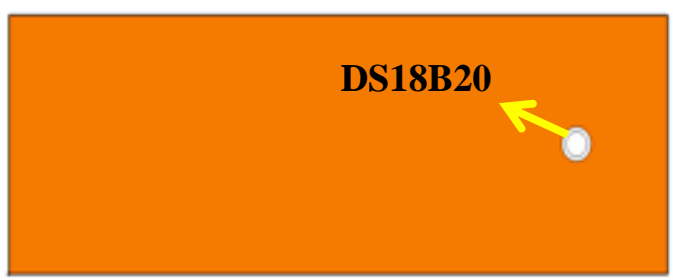

(d)

Gambar 1. Desain perangkat keras monitoring suhu, konsentrasi $\mathrm{O}_{2}$ dan konsentrasi $\mathrm{CO}_{2}$ (a) Desain tampak depan (b) Desain tampak kanan (c) Desain tampak belakang (d) Desain tampak kiri (Hidayatullah, 2020)

Analisis data dilakukaan saat semua data yang diperlukan terkumpul. Data yang diperlukan diantaranya perubahan suhu, perubahan konsentrasi, umur simpan serta susut bobot. Data yang diperoleh selama pengamatan data direkam kemudian ditampilkan dengan langsung tersimpan ke memori internal android dengan format csv. File ini dapat dibuka dari Microsoft Excel. 


\section{Hasil dan Pembahasan}

\subsection{Pengambilan Data}

Pengambilan data umur simpan buah dimulai saat buah mulai diamati sampai mengalami kebusukan yang dilakukan secara realtime yang dikirim dari ESP 8266 ke thingspeak setiap 9 detik, namun mengalami delay sehingga dalam 1 menit data yang terekam dalam thingspeak sebanyak 3 data atau setiap 20 detik. Perbedaan nilai yang tidak terlalu signifikan pada pembacaan per 20 detik menyebabkan data disortir menjadi per hari. Kemudian data dibaca android dengan MIT App Inventor 2 dengan memasukkan alamat web thingspeak dan APIKey thingspeak pada block puzzle MIT App Inventor 2. Setelah itu menampilkan barcode aplikasinya agar bisa dipindai dan diunduh dengan android. Data yang telah direkam kemudian ditampilkan seperti Gambar 2 dengan langsung tersimpan ke memori internal android dengan format csv. File ini dapat dibuka dari Microsoft Excel. Kelemahan dari aplikasi ini jika jaringan data seluler lemah atau tidak ada maka perekaman data akan berhenti, sehingga banyak data yang tidak terekam.

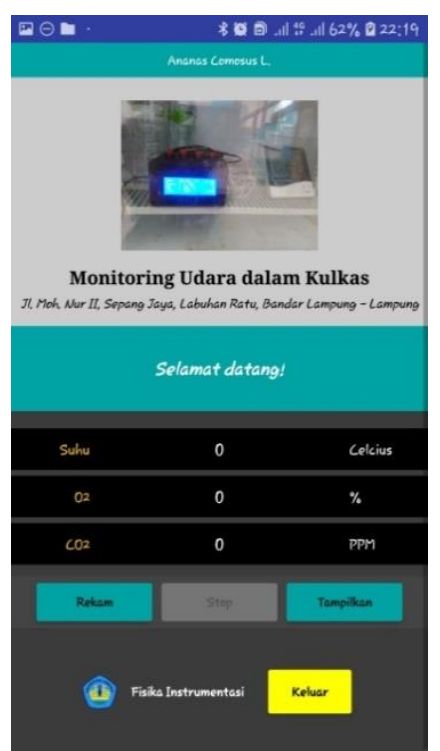

(a)

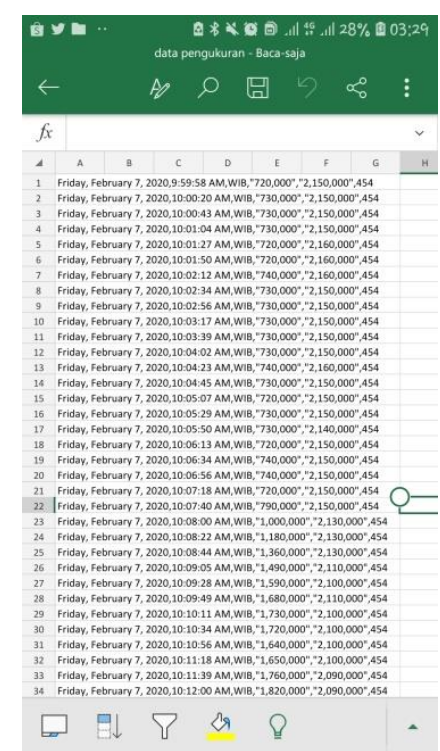

(b)

Gambar 2. Tampilan pada android (a) Tampilan aplikasi pada android; (b) Tampilan data pada android

\subsection{Analisis Data}

Pada penelitian ini data yang diambil diantaranya susut bobot buah nanas matang, susut bobot buah nanas mentah, konsentrasi $\mathrm{CO}_{2}$ dan suhu. Pada Gambar 3 menunjukkan bahwa setiap harinya baik nanas matang maupun nanas mentah nilai susut bobotnya tidak tetap. Pada nanas matang susut bobot tertinggi pada tanggal 26 Februari 2020 sebesar 2,75 \% sedangkan susut bobot tertinggi buah nanas mentah pada tanggal 28 Februari 2020 sebesar 3,52\%. Pada nanas matang ketika buah mendekati akan busuk susut bobot relatif tetap di kisaran $2 \%$ sedangkan nanas mentah mendekati akan busuk langsung melonjak menjadi kisaran $3 \%$.

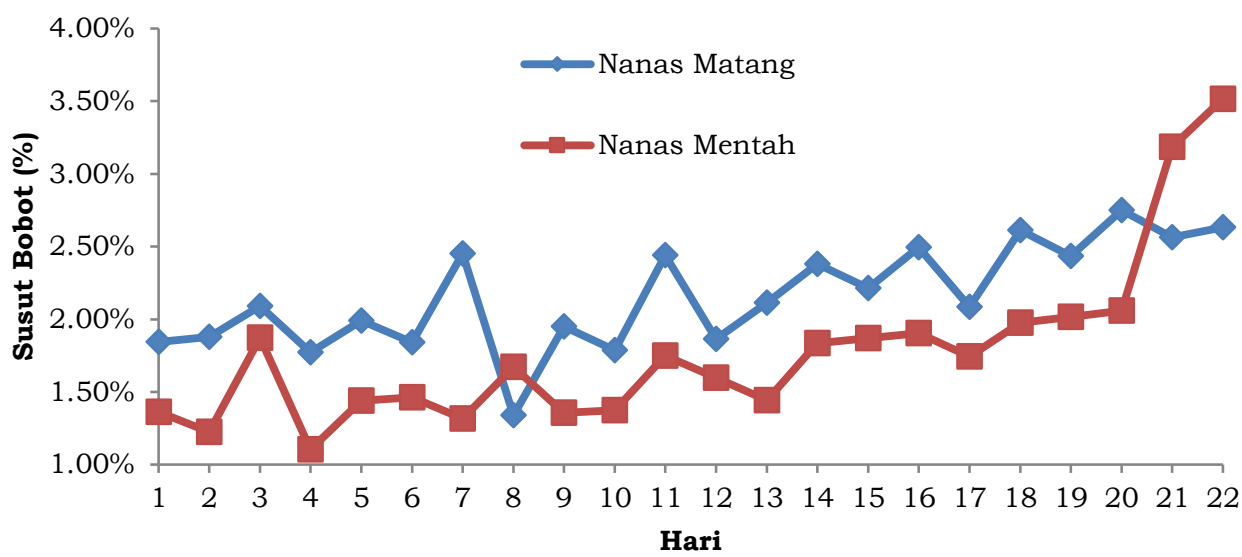

Gambar 3. Grafik susut bobot nanas matang dan nanas mentah 
Nugraeni Y, Suciyati SW, Pauzi GA, dan Supriyanto A, 2020, Analisis Suhu Dan Konsentrasi Karbondioksida dalam Kotak Pendingin Terhadap Susut Bobot dan Umur Simpan Buah Nanas (Ananas Comosus L. Merr) Berbasis MIT App Inventor 2, Jurnal of Energy, Material, and Instrumentation Technology, Vol. 1 No. 3, 2020

Perubahan nanas setiap minggu ditunjukkan pada Gambar 4. Nanas matang maupun nanas mentah mengalami kebusukan saat penyimpanan hari ke 22. Ciri-ciri yang ditunjukkan pada kedua buah nanas yaitu kulit menjadi kecokelatan, daging buah melunak, dan ditumbuhi jamur pada bagian bawah buah nanas. Kebusukan selama penyimpanan disebabkan selama proses penyimpanan buah masih melakukan aktivitas respirasi yang memanfaatkan cadangan makanan yang tersisa. Aktivitas tersebut dapat menyebabkan reaksi metabolisme dalam buah yang dikatalis oleh enzim-enzim dalam buah secara alami sehingga terjadi proses autolisis yang mengakibatkan kerusakan dan kebusukan (Trenggono dkk, 1990).

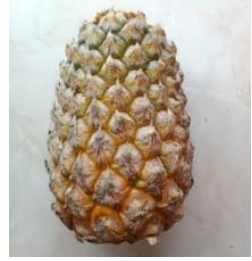

(a) Nanas matang sebelum pengamatan

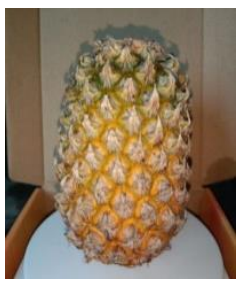

(c) Nanas matang minggu pertama

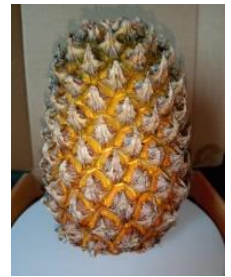

(e) Nanas matang minggu kedua

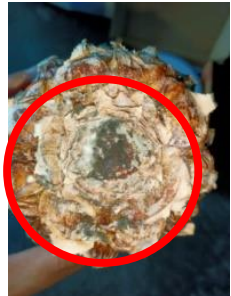

(g) Nanas matang saat busuk

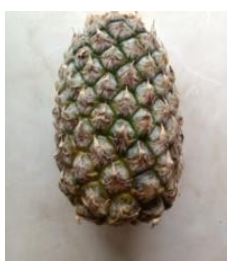

(b) Nanas mentah sebelum pengamatan

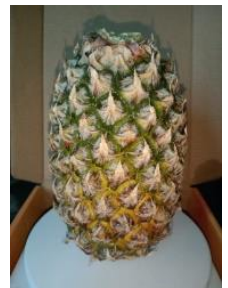

(d) Nanas mentah minggu pertama

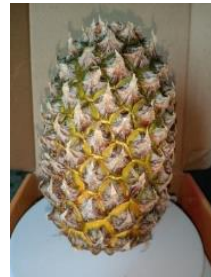

(f) Nanas mentah minggu kedua

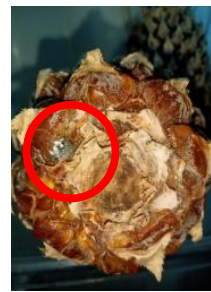

(h) Nanas mentah saat busuk

Gambar 4. Perkembangan kebusukan pada buah nanas setiap minggunya

Gambar 5 menunjukkan bahwa setiap harinya suhu tidak tetap. Suhu terendah pada tanggal 20 Februari 2020 sebesar $7,86^{\circ} \mathrm{C}$ sedangkan suhu tertinggi buah nanas mentah pada tanggal 28 Februari 2020 sebesar 11,05 ${ }^{\circ} \mathrm{C}$. Ketika buah mendekati akan busuk suhu relatif tetap di kisaran $10^{\circ} \mathrm{C}-11^{\circ} \mathrm{C}$. Hal ini sesuai dengan penelitian Paul dan Rohrbach (2002) penyimpanan nanas utuh sebaiknya pada suhu 7,5 - $12{ }^{\circ} \mathrm{C}$ sehingga dapat bertahan 2 -4 minggu.

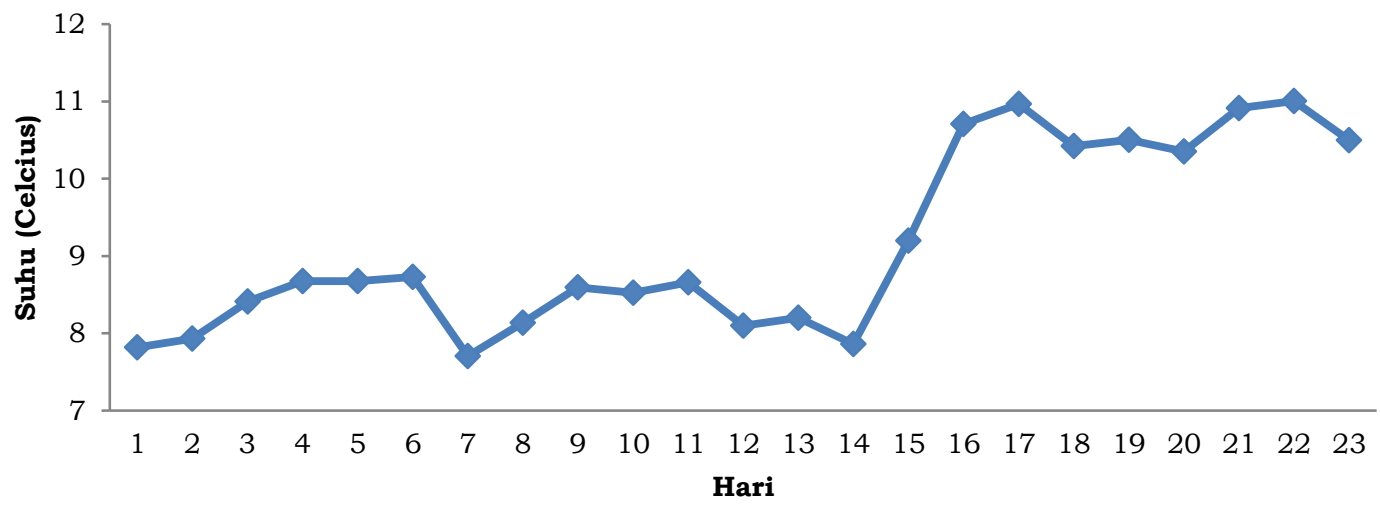


Gambar 5. Grafik data suhu

Pada Gambar 6 menunjukkan bahwa konsentrasi $\mathrm{CO}_{2}$ setiap harinya tidak tetap. Konsentrasi $\mathrm{CO}_{2}$ terendah pada tanggal 7 Februari 2020 sebesar 457,20 ppm sedangkan konsentrasi $\mathrm{CO}_{2}$ tertinggi pada tanggal 28 dan 29 Februari 2020 sebesar 490,77 ppm. Ketika buah mendekati akan busuk konsentrasi $\mathrm{CO}_{2}$ relatif tetap di kisaran $480-490 \mathrm{ppm}$.

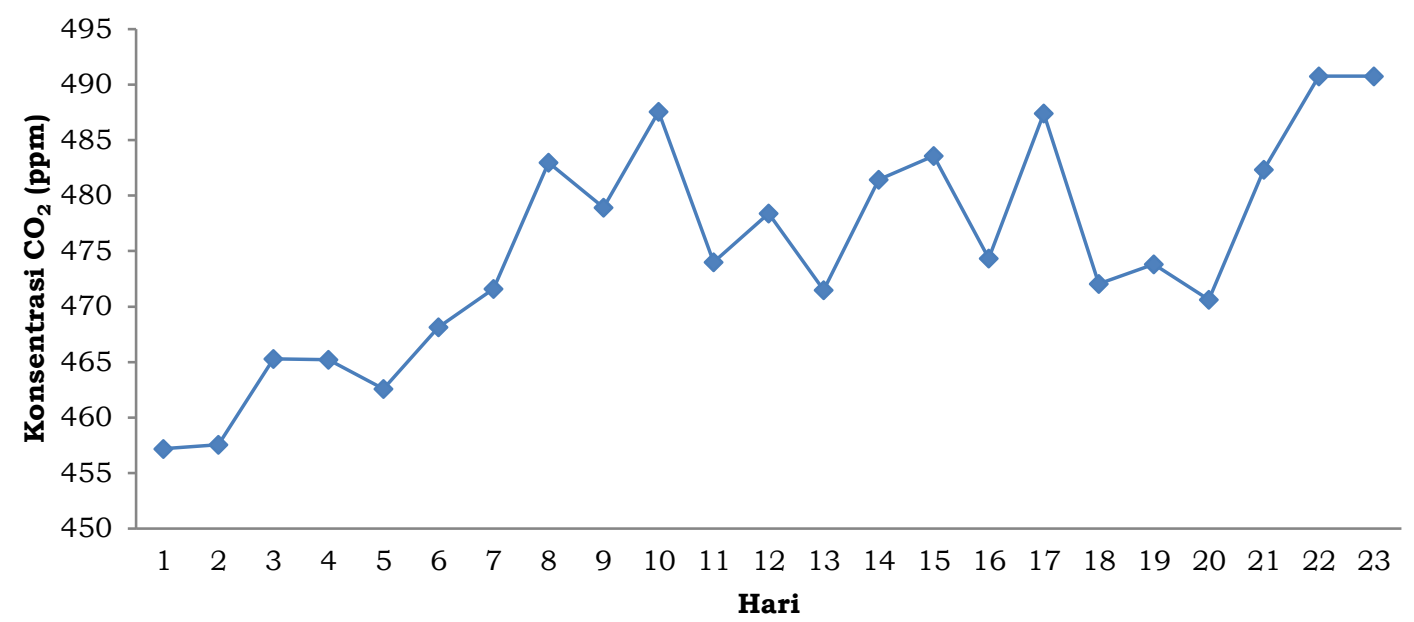

Gambar 6. Grafik data konsentrasi $\mathrm{CO}_{2}$

Pada Gambar 7 menunjukkan bahwa konsentrasi $\mathrm{CO}_{2}$ dan suhu setiap harinya tidak tetap. Konsentrasi $\mathrm{CO}_{2}$ dan suhu selama penyimpanan berpengaruh terhadap susut bobot yang dialami nanas, secara implisit terlihat pada Gambar 3. Dari Gambar 7 terlihat bahwa naik turunnya konsentrasi $\mathrm{CO}_{2}$ dan suhu setiap harinya berdampak pada hasil yang menyebabkan susut bobot tidak terlalu signifikan. Konsentrasi $\mathrm{CO}_{2}$ rendah dapat menghambat proses metabolisme karena saat masa penyimpanan nanas masih mengalami metabolisme yang membutuhkan oksigen dalam pembakaran senyawa yang menghasilkan $\mathrm{CO}_{2}$ dan $\mathrm{H}_{2} \mathrm{O}$. Penyimpanan nanas utuh pada kisaran suhu rendah atau kurang dari $7{ }^{\circ} \mathrm{C}$ dapat menyebabkan chilling Injury. Chilling injury pada buah nanas dapat dilihat dari kulit yang kuning berubah menjadi cokelat, bagian mahkota buah mengering, layu, dan pudar. Buah nanas yang disimpan pada suhu rendah kulit dan mahkotanya dapat mengering karena kehilangan air (Thomson, 2003) sehingga nanas mengalami susut bobot.

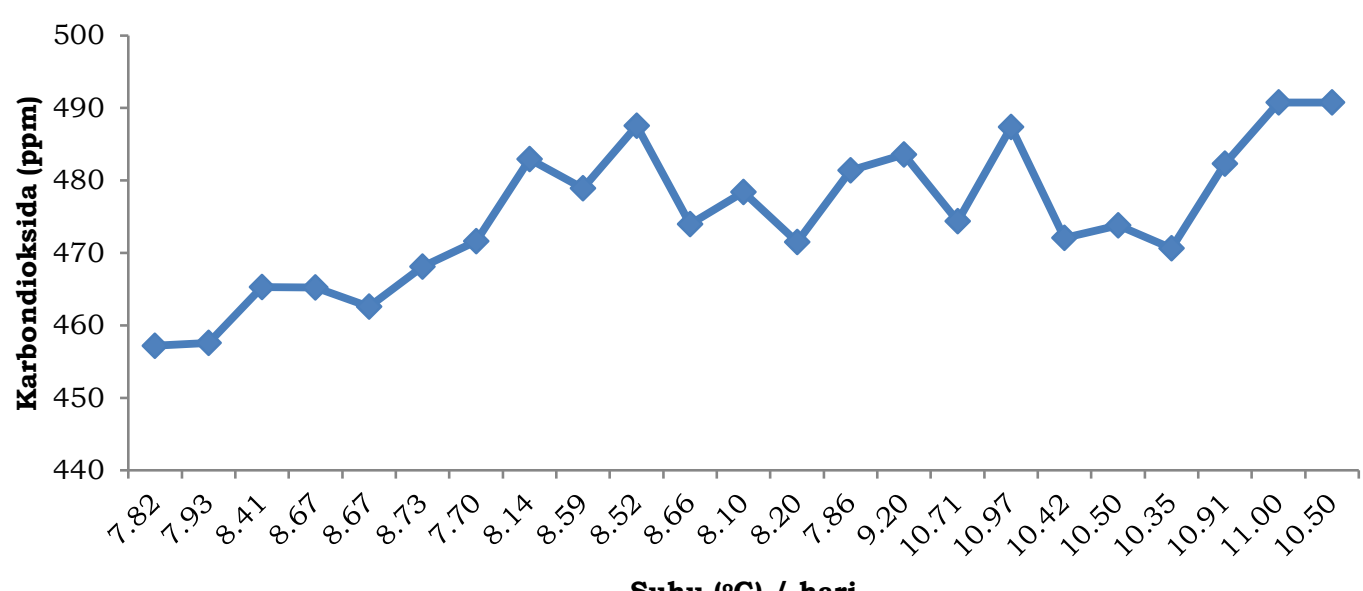

Suhu $\left({ }^{\circ} \mathrm{C}\right)$ / hari

Gambar 7. Grafik hubungan konsentrasi $\mathrm{CO}_{2}$ terhadap suhu setiap hari

\section{Kesimpulan}

Berdasarkan penelitian yang telah dilakukan dan berdasarkan beberapa data penelitian maka dapat disimpulkan bahwa Sistem monitoring konsentrasi $\mathrm{CO}_{2}$ dan suhu pada kulkas telah berhasil mengirimkan data melalui android menggunakan komunikasi wifi melalui aplikasi yang dibuat dengan MIT App Inventor 2. Semakin tinggi konsentrasi $\mathrm{CO}_{2}$ dalam kulkas, umur simpan buah nanas semakin singkat dan susut bobot buah nanas semakin tinggi. Semakin tinggi suhu dalam kulkas, umur simpan buah nanas bertahan semakin singkat dan susut bobot buah nanas semakin tinggi 
Nugraeni Y, Suciyati SW, Pauzi GA, dan Supriyanto A, 2020, Analisis Suhu Dan Konsentrasi Karbondioksida

\section{Daftar Pustaka}

Agustiningrum, D. A., Susilo, B., \& Yulianingsih, R. 2014. Studi Pengaruh Konsentrasi Oksigen pada Penyimpanan Atmosfer Termodifikasi Buah Sawo (Achras zapota L.). Jurnal Bioproses Komoditas Tropis, 2(1), 22-34.

Argo, B. D., Lastriyanto, A., \& Astuti, N. P. 2010. Sistem Monitoring Gas Oksigen dan Karbondioksida pada Ruang Penyimpanan Sistem Udara Terkontrol. Rekayasa Mesin, 1(3), 84-90.

Hidayatullah, M. S. 2020. Rancang Bangun Sistem Akuisisi Data Suhu, Gas Oksigen $\left(\mathrm{O}_{2}\right)$, dan Karbon Dioksida $\left(\mathrm{Co}_{2}\right)$ pada Ruang Penyimpanan Buah Nanas Berbasis Arduino. Skripsi. Universitas Lampung. Bandar Lampung.

Paul dan Rohrbach. 2002. The Pineapple: Botany, Production, and Uses. CABI Publishing. Cambridge MA USA. 239 pp.

Widyaningrum, Yohanes Aris Purwanto, Sutrisno Mardjan. 2018. Desain Sistem Kontrol dan Monitoring Kondisi Udara pada Controlled Atmosphere Storage Berbasis Mikrokontroler Arduino Uno. Jurnal Keteknikan Pertanian. STTP Manokwari.

Winarno F.G. 2004. Kimia Pangan dan Gizi. Gramedia Pustaka Utama. Jakarta.

Trenggono, Z. Noor, D. Wibowo, M. Gardjito, M. Astuti,. 1990. Kimia, Nutrisi Pangan.Pusat Antar Universitas Pangan danGizi UGM. Yogyakarta.

Thomson, A. K. 2003. Fruit and Vegetables: Harvesting, Handling and Storage. Second ed. Blackwell Publishing Ltd. Australia. 308 pp. 